\title{
P05.56. Prescribing nature: a content analysis of qualitative responses among park users by socio- demographics and patterns of use
}

\author{
K Irvine ${ }^{1 *}$, M Dallimer $^{2}$, S Warber ${ }^{3}$ \\ From International Research Congress on Integrative Medicine and Health 2012 \\ Portland, Oregon, USA. 15-18 May 2012
}

\section{Purpose}

Against a backdrop of increasing interest in 'prescribing nature' to promote health and well-being, this study investigated the extent to which adult users of urban greenspace endorsed health benefits and whether these effects differed between groups or frequency of use.

\section{Methods}

In situ questionnaires were delivered face-to-face to 1108 users (54\% response rate) of urban riverscapes in Sheffield, UK. First mentioned responses to an openended question about how they felt after leaving the area were content analysed. Resultant codes were grouped into themes and domains and quantified. Using Chi-square tests, response-patterns were compared across age, gender, visit frequency, number of people in the group, or whether walking a dog.

\section{Results}

Comments from participants (92\% European ethnicity, $62 \%$ male, aged $16-70+$ years) primarily classified into emotional (38\%), physical (34\%), and spiritual (22\%) domains of health. Cognitive (3\%) and overall health (3\%) domains were rarely first mentioned; mention of social health did not occur. Emotional included feelings within the self (happy, wonderful), amplified by feelings toward the greenspace itself (appreciation, sadness about condition). Relaxation featured prominently as a derived physical effect; tranquillity was strongly present within spiritual. Across the frequently mentioned domains, differences existed for gender $(p=0.021)$, age $(p<0.001)$ and whether participants were alone $(\mathrm{p}=0.001)$. Women more frequently mentioned spiritual; participants in their 20 s or 50 s identified aspects of physical health; being alone brought out feelings of place attachment. No significant differences were found for visit frequency (daily, weekly, monthly, less than monthly; $\mathrm{p}=0.304$ ) or whether walking a $\operatorname{dog}(\mathrm{p}=0.392)$.

\section{Conclusion}

Greenspace provided multiple effects, primarily relaxation, positive emotions and tranquility, which promote human well-being. While specific groups of users obtained different effects, there was no evidence of a differentiated effect depending on visit frequency. This fine-grained analysis suggests useful guidelines for the development of nuanced, rather than generic, 'nature prescriptions'.

\section{Author details}

${ }^{1}$ De Montfort University, Leicester, United Kingdom. 2University of Copenhagen, Copenhagen, Denmark. ${ }^{3}$ University of Michigan, Ann Arbor, USA.

Published: 12 June 2012

doi:10.1186/1472-6882-12-S1-P416

Cite this article as: Irvine et al:: P05.56. Prescribing nature: a content analysis of qualitative responses among park users by socio-

demographics and patterns of use. BMC Complementary and Alternative Medicine 2012 12(Suppl 1):P416.

${ }^{1}$ De Montfort University, Leicester, United Kingdom

Full list of author information is available at the end of the article

(C) 2012 Irvine et al; licensee BioMed Central Ltd. This is an Open Access article distributed under the terms of the Creative Commons Attribution License (http://creativecommons.org/licenses/by/2.0), which permits unrestricted use, distribution, and reproduction in any medium, provided the original work is properly cited. 